\title{
Please pay attention to the competency of Chinese primary clinical medical workers in electrocardiogrophic interpretation skills
}

\section{Yu-lei Gao ( $\sim$ gaoyulei828@126.com )}

Tianjin Medical University General Hospital https://orcid.org/0000-0003-3099-2963

\section{Yan-hua Li}

Tianjin Medical University General Hospital

Jie Li

Tianjin Medical University General Hospital

\section{Chun-xue Wang}

Tianjin Medical University General Hospital

\section{Yan-cun Liu}

Tianjin Medical University General Hospital

\section{Chen Li}

Tianjin Medical University General Hospital

\section{Ying Yao}

Tianjin Medical University General Hospital

\section{Song-tao Shou}

Tianjin Medical University General Hospital

\section{Yan-fen Chai}

Tianjin Medical University General Hospital

\section{Research article}

Keywords: Hierarchical diagnosis and treatment services, Electrocardiogram, Primary clinical medical workers, Interpretation skills, Improve

Posted Date: December 12th, 2019

DOl: https://doi.org/10.21203/rs.2.18691/v1

License: () (1) This work is licensed under a Creative Commons Attribution 4.0 International License. Read Full License 


\section{Abstract}

Background: Improving the capacity of health care, disease diagnosis and treatment of primary medical workers was the key to hierarchical diagnosis and treatment services. Electrocardiogram (ECG) played an important role in the diagnosis of cardiac diseases and should be regarded as the most basic tool for primary clinical medical workers in China.

Objectives: To investigate the competency of Chinese medical workers in electrocardiographic interpretation skills, especially in the primary care hospitals, to explore the insufficiency of electrocardiographic interpretation skills and the improvement methods.

Methods: A cross-sectional questionnaire study was conducted via the internet from March to October 2019. The questionnaire consists of 6 parts: basic information, equipping with an electrocardiograph, operating electrocardiograph, receiving electrocardiographic theory, testing of electrocardiographic interpretation, and improving electrocardiographic interpretation skills.

Results: The effective quantity of this questionnaire was 2307 , with an effective rate of $96.57 \%$. The overall reliability was $\alpha=0.895$. There were no significant differences among primary, private and class- $\varangle$ hospitals in the aspects of equipping with an electrocardiograph $(\chi 2=3.794,3.104, P \llbracket 0.05)$, operating the electrocardiograph $(\chi 2=1.857, P \llbracket 0.05)$ and receiving electrocardiographic theoretical study $(\chi 2=6.701, P \rrbracket$ 0.05). Medical workers in private and class- $\square$ hospitals had a stronger interpretation competency of ECG, including common or life-threatening ECGs (P凶0.01). The development of talent echelon in primary hospitals affected the electrocardiographic interpretation skills of medical workers (P凶0.01). In primary hospitals, the age was mainly $\geq 40$ years $(79.0 \%)$, the education background was mainly bachelor and below degree $(80.9 \%)$, the professional qualification was mainly physician assistant $(58.6 \%)$ and primary physician (31.4\%). The interpretation competency of ECG of medical workers in private or class- $\mathbb{Z}$ hospitals was higher than that in primary hospitals ( $\mathrm{P} \otimes 0.05$ or 0.01$)$.

Conclusions: In China, the examination of electrocardiograph had been popularized. Due to the unreasonable development of talent echelon in primary hospitals, the electrocardiographic interpretation skills of primary medical workers were worrying. We should improve electrocardiographic teaching methods with the help of the internet, to enhance the electrocardiographic interpretation skills of primary medical workers.

\section{Background}

The 17th National People's Congress (NPC) of China adopted "every citizen enjoys basic medical and health services" as the goal of the reform and development of medical and health undertakings, and focused on the principle of "ensuring basic medical treatment, strengthening the construction of primary care hospitals, improving the construction of mechanism" to solve the problem of "difficult and expensive medical treatment". The 18th NPC of China further proposed "reasonable allocation of medical and health resources, construction of hierarchical diagnosis and treatment service system", which pointed out 
the direction for the reform of medical and health service system and basic medical security system. The connotation of hierarchical diagnosis and treatment is "the disease was first diagnosed in primary hospitals, two-way referral, the separate treatment of critical and chronic diseases, and interaction between upper and lower hospitals" [1]. Improving the diagnosis and treatment competency of diseases of primary care medical workers is the key prerequisite to achieving hierarchical diagnosis and treatment service. Otherwise, even if the policy is carried out, primary care hospitals can't meet the needs of disease prevention and treatment.

ECG has been applied in clinical work for more than 100 years, and it is still the most easily available, the cheapest and the most important irreplaceable diagnostic tool in cardiology [2]. ECG is a technique that records the patterns of depolarization and repolarization of cardiomyocyte electrical activity during each cardiac cycle [3]. Electrocardiographic abnormalities are frequently the first manifestation of arrhythmia, myocardial ischemia, myocardiopathy, electrolyte metabolism, poisoning and coma, especially serious life-threatening arrhythmia and other critical patients [2-6]. ECG is also used in preventive health care and is an important tool for screening people at high risk of sudden death $[2,6-7]$. The right manner of electrocardiographic interpretation should be the basic skill of every clinical medical worker, especially the life-threatening ECG. Misinterpretation of an ECG can lead to misdiagnosis and mistreatment, even lifethreatening. Statistics show that 10,000 people die every year in the USA from ECG misinterpretation [8]. Other studies have shown that 3.6 percent of patients are misdiagnosed with atrial fibrillation each year and inadequately administration of antiarrhythmic and anticoagulant medications [9].

With the increasingly serious aging problem in China, coronary heart disease (CHD), diabetes, hypertension, and other chronic diseases have gradually become the main diseases affecting health [10]. In China, primary care hospitals generally include clinics, Class-I and Class- $\square$ Hospitals. The medical technology and quality of primary care hospitals are still relatively weak, and even in the situation of "a stethoscope, a sphygmomanometer and a thermometer", which is difficult to accommodate the growing medical needs and the implementation of the hierarchical diagnosis and treatment system.

Electrocardiograph is still the most powerful examination tool in primary care hospitals $[2,11]$. Primary care medical workers can perform electrocardiographic examination for patients with chest pain, chest stufly, abnormal breathing, palpitations or dizziness at any time, diagnosing life-threatening diseases and informing the superior hospital through communication devices in a timely manner, so as to shorten the time of first-aid for life-threatening diseases, such as patients with ST-Elevation Myocardial Infarction (STMI) $[2,4-6,11]$. Primary medical workers can also evaluate the condition assessment and health guidance of patients with chronic diseases, such as CHD, through electrocardiographic examination $[6$, $11]$.

To investigate and assess the competency of Chinese clinical medical workers in electrocardiographic interpretation skills, especially in the primary care hospitals, in order to explore the insufficiency of electrocardiographic interpretation ability of primary clinical medical workers and the improvement methods. 
Hence, using a cross-sectional structured questionnaire study, we investigated and assessed the equipment of electrocardiograph in primary care hospitals, the competency of primary clinical medical workers to operate electrocardiograph, and the competency of Chinese clinical medical workers in electrocardiographic interpretation skills, especially in the primary care hospitals. We further analyzed the reasons that affect the competency of electrocardiographic interpretation skills of primary medical workers.

\section{Methods}

\section{Design questionnaire}

This cross-sectional questionnaire study was a structural questionnaire and conducted via the internet between march and October 2019. There were 6 parts in this questionnaire. Part 1, basic information: province or municipality, age, education background, occupational identity, professional qualifications and the level of the hospital. Part 2, whether hospitals or departments were equipped with an electrocardiograph. Part 3, whether skilled in operating electrocardiograph. Part 4, whether having received electrocardiographic theory. Part 5 , the competency of electrocardiographic interpretation, and this part contains three aspects. Firstly, we selected 20 types of ECGs commonly interpreted in clinical practice, and then the respondents were asked to evaluate themselves. According to whether it affects hemodynamics and life-threatening, each ECG score was performed, as shown in table 1 [2,6,12-14]. Secondly, we selected 10 types of ECGs commonly interpreted in critically ill patients, and then the respondents were asked to evaluate themselves. According to the severity of hemodynamic disturbance and life-threatening, each ECG score was performed, as shown in table 2 [2,6,12-14]. Finally, we selected

10 typical ECGs commonly used in clinical work to test respondents, and each electrocardiogram was setting 6 options. According to the severity of hemodynamic disturbance and life-threatening, each ECG score was performed, as shown in table $3[2,6,12-14]$. Part 6 , the methods to improve the competency of electrocardiographic interpretation.

\section{Respondents}

The questionnaire was conducted via the internet platform -Wenjuanxing from march to October 2019. The internet address is https://www.wj..cn/m/34324651.aspx. Inclusion criteria for respondents: Medical workers engaged in clinical work in hospitals or clinics at various levels. Has the clinical practitioner qualification certificate. More than 2 years of working experience. Volunteer for this questionnaire. Be able to fill in the questionnaire realistically.

\section{Exclusion criteria}

We had set up a dedicated questionnaire survey team, including investigators, questionnaire online instructors, data entry clerks, data auditors, and data analysts. The exclusion criteria for this questionnaire were: Using the same IP address to complete the questionnaire. The whole questionnaire 
was filled in with the same option. It was not consistent with the inclusion criteria of the questionnaire. More than two-thirds of the questions were unanswered.

\section{Statistical analysis}

All the data were statistically analyzed by the software of IBM SPSS Statistics 24. Cronbach's a was used to test the reliability of the questionnaire. Measurement data were represented as mean \pm standard deviation (SD). Enumeration data were represented as numbers and percentages. The one-way ANOVA test was used for the comparison of measurement data, and the $c^{2}$ test was used for the comparison of enumeration data. A $P$-value of 0.05 or 0.01 was considered statistically significant.

\section{Results}

\section{Description of the sample}

A total of 2,389 questionnaires were collected, among which 2,307 were effective, with an effective rate of $96.57 \%$. The overall Cronbach's a of this questionnaire was 0.895 , greater than 0.80 , indicating that this questionnaire has good reliability. As shown in table 4, the respondents were mainly distributed in north China (894, 38.7\%), the age of respondents was mainly between 40 and $50(1007,43.6 \%)$, the respondents' educational background was mainly focused on bachelor's degree and below (bachelor degree: $800,34.7 \%$. junior college and below: $759,32.9 \%)$, most of them are clinicians $(1927,83.5)$, the respondents were mainly physician assistants $(993,43 \%)$, and the respondents were mainly in class- $\mathbb{}$ hospitals $(1117,48.4 \%)$.

\section{The examination of electrocardiograph has been popularized in China}

We analyzed whether the hospitals or departments in which the respondents worked were equipped with an electrocardiograph, as shown in table 5 . Almost all hospitals were equipped with an electrocardiograph, there were no significant differences among primary hospitals (97.4\%), private

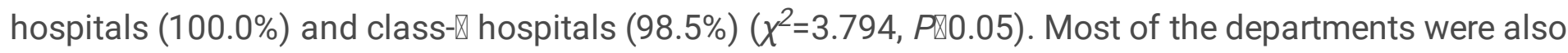
equipped with an electrocardiograph, there were no significant differences among primary hospitals (81.7\%), private hospitals $(87.4 \%)$ and class- $\square$ hospitals $(84.5 \%)\left(\chi^{2}=3.104, P \otimes 0.05\right)$. Almost all medical workers could operate the

electrocardiograph, there were no significant differences among primary hospitals (92.9\%), private

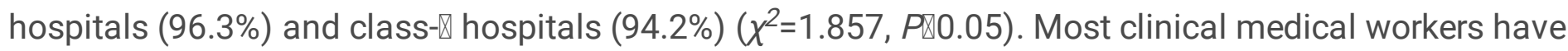
received a theoretical study on ECG, there were no significant differences among primary hospitals (76.9\%), private hospitals (78.1\%) and class- $\square$ hospitals $(71.2 \%)\left(\chi^{2}=6.701, P \otimes 0.05\right)$.

\section{Improving the interpretation competency of ECG of primary medical workers}

The competency of respondents in electrocardiographic interpretation was scored according to the developed Scoring criteria (table 1-3), and the scores of medical workers were further analyzed according 
to the level of hospitals, as shown in Fig.1. Firstly, the respondents were asked to self-assessed 20 types of commonly ECGs and 10 types of life-threatening ECGs. As show in Fig.1 A and B, compared with medical workers in primary hospitals, medical workers in private and class- $₫$ hospitals were better able to interpret commonly or life-threatening ECGs $(P \otimes 0.01)$, there was no significant difference between medical

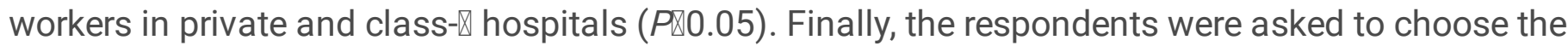
correct interpretation of the 10 types of electrocardiographic images that we provided. As shown in Fig. 1 C, compared with medical workers in primary hospitals, medical workers in private and class- $\square$ hospitals were able to more accurately interpret electrocardiographic images $(P \otimes 0.01)$, there was no significant difference between medical workers in private and class- $₫$ hospitals $(P \otimes 0.05)$. As show in Fig.1 D, further analyzed the total

score of the two parts of the appeal, the interpretation competency of ECG of medical workers in private or class- $₫$ hospitals was higher than that of medical workers in primary hospitals ( $P \otimes 0.01)$, there was no significant difference between medical workers in private and class- $₫$ hospitals ( $P ख 0.05)$.

\section{The effect of basic information on the electrocardiographic interpretation skills of medical workers}

The basic information which we defined as a medical worker, included age, educational background, occupational identity, and professional qualification. The total score of electrocardiographic selfassessment and test, which represented the interpretation competency of ECG of medical workers. As shown in Fig.2 A, with the increasing of age, the electrocardiographic interpretation skills of medical workers gradually decreased, compared with medical workers aged 20-30 years, the electrocardiographic interpretation skills of medical workers aged over 40 years was significantly decreased $(P \otimes 0.05)$, especially $\geq 50$ years old $(P \otimes 0.05)$. As shown in Fig. $2 \mathrm{~B}$, compared with medical workers with the education background of junior college and below, medical workers with the education background of bachelor degree could significantly improve their electrocardiographic interpretation skills $(P \otimes 0.01)$, there were no significant differences among the education background of bachelor, master and doctoral Degree $(P \otimes 0.05)$. As shown in Fig. $2 \mathrm{C}$, occupational identity did not significantly affect the electrocardiographic interpretation skills of medical workers, there was no significant difference between the electrocardiographic interpretation skills of doctor and nurse (P凶0.05). As shown in Fig. $2 \mathrm{D}$, with the increasing of professional qualification, the electrocardiographic interpretation skills of medical workers gradually increased, compared with the primary physician, the electrocardiographic interpretation skills of medical workers with the professional qualification of intermediate physician was significantly ibcreased ( $P \otimes 0.01)$, especially senior physician ( $P \otimes 0.01)$.

\section{The talent development of primary hospitals was worrying}

We analyzed the basic information about medical workers at all levels of

hospitals. As shown in table 6 , The age of medical workers in primary hospitals was mainly $\geq 40$ years old (79.0\%), but in class- $\$ hospitals, it was mainly between 30 and 50 years old (71.4\%), there were significant differences in the distribution of primary and class- $\varnothing$ hospitals in all age groups $\left(\chi^{2}=50.93\right.$, 
$147.51,661.05,621.39, P \otimes 0.01)$. As shown in table 7 , The education background of medical workers in

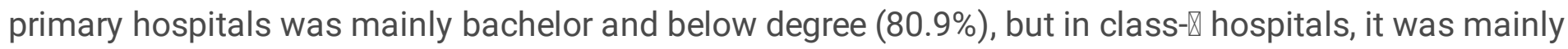
bachelor and above degree (91.0\%), there were significant differences in the distribution of primary and class- $\square$ hospitals in all education background groups $\left(\chi^{2}=1175.91,328.97,186.05,238.24, P \otimes 0.01\right)$. As shown in table 8 , The professional qualification of medical workers in primary hospitals was mainly physician assistant (58.6\%) and primary physician (31.4\%), but in class- $\square$ hospitals, it was mainly intermediate physician (41.5\%), there were significant differences in the distribution of primary and class$\otimes$ hospitals in all professional qualification groups $\left(\chi^{2}=1326.41,591.41,131.50,99.61,154.36, P \otimes 0.01\right)$.

\section{The worrying talent development hindered the electrocardiographic interpretation skills of primary medical workers}

As shown in Fig. 3, in the same age, educational background and professional qualification conditions, the interpretation competency of ECG of medical workers in private or class- $\square$ hospitals was higher than that of medical workers in primary hospitals ( $P \otimes 0.05$ or 0.01 ), there was no significant difference between medical workers in private and class- $₫$ hospitals $(P \otimes 0.05)$.

\section{How to improve the electrocardiographic interpretation skills of medical workers?}

As shown in table 9, almost all medical workers believed that electrocardiographic interpretation skills were helpful for clinical work (99.1\%). More than $80 \%$ of medical workers believed that characteristics of ECG in various diseases (89.5\%), repeating clinical practice $(82.9 \%)$, and combining practice with theory $(83.3 \%)$ were the key to improve the electrocardiographic interpretation skills. $74.8 \%$ of the medical workers believed that improving electrocardiographic teaching methods for medical students was helpful to improve electrocardiographic interpretation skills. $71.5 \%$ of the medical workers chosen the internet as a way to improve the electrocardiographic interpretation skills.

\section{Discussion}

We believed that this was the first questionnaire about electrocardiographic equipment and the electrocardiographic interpretation skills of medical workers in China. To our delight, the examination of electrocardiograph had been popularized. Almost all hospitals and departments were equipped with an

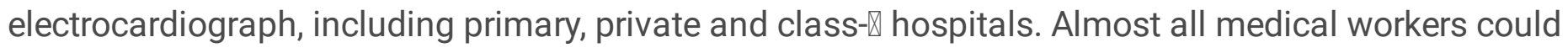
operate the electrocardiograph and have received a theoretical study on ECG. Classification, which according to the severity of diseases and the difficulty of treatment, was the essence of hierarchical diagnosis and treatment service system $[1,10]$. Medical institutions with different service capacities undertaken the treatment of different diseases and carried out timely and convenient referrals according to the changing conditions of patients [1]. Primary hospitals had low medical equipment configuration and poor medical environment. Electrocardiograph is the most easily available, the cheapest and the most important irreplaceable diagnostic tool in any medical place [2-4]. More and more primary medical units are equipped with an electrocardiograph, and more and more primary medical workers are qualified 
to perform an electrocardiographic examination for patients. Therefore, it is necessary to have the interpretation competency of ECG, especially in rescuing critically ill patients.

ECG is an important reference for diagnosis, prevention, and evaluation of diseases [2-9]. Accurate diagnosis is the prerequisite for effective treatment, and ECG can be used as an auxiliary reference for the diagnosis of many diseases, especially in primary medical units and pre-hospital emergency treatment where laboratory examination and other means are lacking[15-17]. In the current study, we showed that

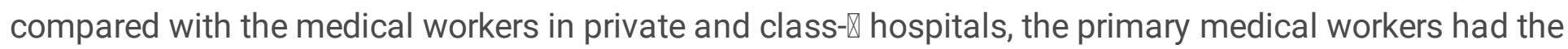
lower interpretation competency of ECG, including commonly or life-threatening ECGs. Shortening reperfusion time is essential to reduce the necrotic area and cardiovascular events in STMI, which diagnosed according to chest pain and other symptoms, ECG and the change of myocardial enzyme [5, 18]. Therefore, improving the interpretation competency of ECG of primary medical workers could shorten the rescue time of life-threatening diseases.

In China, the rural population base is huge and rural medical talents are in great demand. In recent years, with the rapid development of the economy, more and more young people with high education background choose to move from the countryside to the city, which makes the rural medical "no successor" $[1,10]$. In the current study, we showed that the development of talent echelons of primary hospitals was worrying, which characterized by older age, lower educational background, and lower professional qualification. We further analyzed the influence of talent echelon on the electrocardiographic interpretation skills of primary medical workers and demonstrated that the worrying talent development hindered the electrocardiographic interpretation skills of primary medical workers. In the same age, educational background or professional qualification conditions, the interpretation competency of ECG of medical workers in private or class- $₫$ hospitals was higher than that in primary hospitals. According to Han and colleagues' investigation, most of the patients sought treatment in class- $₫$ hospitals, which accounts for $63.7 \%$ of the total outpatient volume, while the outpatient volume of primary hospitals accounts for $36.3 \%$, especially community medical service stations, which only account for $6.3 \%$ [19]. Previous studies have shown that at least $33 \%$ of ECGs, even experienced cardiologists, had serious misinterpretation. The correct interpretation of electrocardiogram required not only a profound knowledge of electrocardiogram but also rich clinical experience $[2,20]$. A large number of patients poured into class$\nabla$ hospitals for treatment, resulting in the lack of clinical experience of medical workers in primary hospitals.

Although electrocardiographic interpretation was a basic skill for clinical medical workers, the best teaching method for improving the interpretation of ECG had not been determined [21-22]. The basic theory of ECG was abstruse, the image characteristics of ECG were scattered and complicated, and the manifestations of pathological electrocardiogram were multifarious [23-24]. For reasons discussed above, reduced the enthusiasm of medical workers to learn ECG, and also caused the psychological resistance, even some medical workers chose to give up the study. Training medical students to develop a good habit of electrocardiographic interpretation, which was the key to improve the electrocardiographic interpretation skills of clinical medical workers, reduced the error rates of electrocardiographic 
interpretation [21-22]. Just as we did in this questionnaire, $74.8 \%$ of the medical workers believed that improving electrocardiographic teaching methods for medical students was helpful to improve electrocardiographic interpretation skills. Through the multimedia teaching, the discussion of the picture, the team cooperation analysis, computer-human interaction model, combining of theory with the clinical case, and so on, gradually cultivating the interest of medical students, letting the medical student active study, arousing the medical student to master the enthusiasm of electrocardiographic interpretation ability[21-22, 25-26].

\section{Conclusions}

Hierarchical diagnosis and treatment services have pointed out the direction for the reform of China's medical and health service system and the basic medical security system. At present, in China, including hospitals and departments, the examination of electrocardiograph had been popularized. However, due to the unreasonable development of talent echelon in primary hospitals, the electrocardiographic interpretation skills of primary medical workers were worrying. We should improve electrocardiographic teaching methods with the help of an internet platform, in order to enhance the electrocardiographic interpretation skills of primary medical workers, which was conducive to the implementation of our hierarchical diagnosis and treatment services system.

\section{Abbreviations}

ECG:Electrocardiogram; NPC:National People's Congress; CHD:Coronary heart disease; STMI:ST-Elevation Myocardial Infarction.

\section{Declarations}

\section{Acknowledgments}

We thank professor Shu-Zhang Cui of the Emergency Department of Tianjin Medical University General Hospital for the guidance of experimental design.

\section{Funding}

Funding for research assistants and the collection of data was provided by grants from Tianjin Medical University General Hospital (Nos. ZYYFY2015020, ZYYFY2014014) and Chinese association of emergency physicians (Nos. 2016020). Tianjin Medical University General Hospital and Chinese association of emergency physicians played no role in the design of the study, analysis, and interpretation of data, as well as in writing the manuscript.

\section{Availability of data and materials}

This questionnaire was conducted and obtained via the internet--Wenjuanxing platform. The internet address of the Wenjuanxing platform is https://www.wjx.cn/m/34324651.aspx. The datasets generated 
during the current study are available via the Wenjuanxing platform. All data generated or analyzed during this study are included in this published article.

\section{Authors' contributions}

YLG, YHL, and JL contributed equally to this work, they conceived the study with YFC and STS commenting on the study design. CXW and YCL acquired the data from questionnaires and been as questionnaire online instructors. YLG, YHL, and CL conducted the statistical analysis and interpretation of the data. YY advised on the statistical analysis. YLG wrote the first draft with support from JL. All authors reviewed the manuscript and made critical changes for intellectual content. All authors read and approved the final manuscript.

\section{Ethics approval and consent to participate}

Participants were informed that their optional and anonymous survey results would be used in this study. All of the participants agreed to use the survey data for study and publication. All procedures were approved by the Scientific Investigation Board, Tianjin Medical University General Hospital, Tianjin, China. The research would not adversely affect individual privacy rights and welfare. There was no way to associate any participant with their survey results.

\section{Consent for publication}

Not applicable.

\section{Competing interests}

The authors declare that they have no competing interests.

\section{Author details}

${ }^{1}$ Department of Emergency Medicine, Tianjin Medical University General Hospital, Tianjin 300052, P. R. China

${ }^{2}$ Department of Emergency Medicine, Binhai Hospital, Tianjin Medical University General Hospital, Tianjin 510370, P. R. China

${ }^{3}$ Department of Emergency Medicine, Airport Hospital, Tianjin Medical University General Hospital, Tianjin 300450, P. R. China

\section{References}

1. Zhang R, Xing Y, Wang J, Shang X, Zhu X. A Novel Multiattribute Decision-Making Method Based on Point-Choquet Aggregation Operators and Its Application in Supporting the Hierarchical Medical Treatment System in China. Int J Environ Res Public Health. 2018;15: E1718. 
2. Begg G, Willan K, Tyndall K, Pepper C, Tayebjee M. Electrocardiogram interpretation and arrhythmia management: a primary and secondary care survey. Br J Gen Pract. 2016;66:291-6.

3. Nunes de Alencar Neto J, Baranchuk A, Bayés-Genís A, Bayés de Luna A. Arrhythmogenic right ventricular dysplasia/cardiomyopathy: an electrocardiogram-based review. 2018;20: 3-12.

4. Simard C, Schwartz BC. An Electrocardiogram-Based Diagnosis of Coma. Am J Med. 2019;132:735736.

5. Han C, Shi L. ML-ResNet: A novel network to detect and locate myocardial infarction using 12 leads ECG. Comput Methods Programs Biomed. 2019;185:105138.

6. Boyle NG, Vohra JK. The Enduring Role of the Electrocardiogram as a Diagnostic Tool in Cardiology. J Am Coll Cardiol. 2017;69:1704-6.

7. McKinney J, Johri AM, Poirier P, Fournier A, Goodman JM, Moulson N, et al. Canadian Cardiovascular Society Cardiovascular Screening of Competitive Athletes: The Utility of the Screening Electrocardiogram to Predict Sudden Cardiac Death. Can J Cardiol. 2019;35:1557-66.

8. Mele PF. The ECG dilemma: guidelines on improving interpretation. J Healthc Risk Manag. 2008;28:27-31.

9. Bogun F, Anh D, Kalahasty G, Wissner E, Bou Serhal C, Bazzi R, et al. Misdiagnosis of atrial fibrillation and its clinical consequences. Am J Med. 2004;117:636-42.

10. Lv Q, Jiang Y, Qi J, Zhang Y, Zhang X, Fang L, et al. Using Mobile Apps for Health Management: A New Health Care Mode in China. JMIR Mhealth Uhealth. 2019;7:e10299.

11. Hornick J, Costantini O. The Electrocardiogram: Still a Useful Tool in the Primary Care Office. Med Clin North Am. 2019;103:775-84.

12. Hotradat M, Balasundaram K, Masse S, Nair K, Nanthakumar K, Umapathy K. Empirical mode decomposition based ECG features in classifying and tracking ventricular arrhythmias. Comput Biol Med. 2019;112:103379.

13. Scheirlynck E, Van Malderen S, Motoc A, Lie ØH, de Asmundis C, Sieira J, et al. Contraction alterations in Brugada syndrome; association with life-threatening ventricular arrhythmias. Int $\mathrm{J}$ Cardiol. 2019;5273:32197-7.

14. Oh SL, Ng EYK, Tan RS, Acharya UR. Automated beat-wise arrhythmia diagnosis using modified U-net on extended electrocardiographic recordings with heterogeneous arrhythmia types. Comput Biol Med. 2019;105:92-101.

15. Schmidt FP, Perne A, Hochadel M, Giannitsis E, Darius H, Maier LS, et al. Characterization and referral patterns of ST-elevation myocardial infarction patients admitted to chest pain units rather than directly to catherization laboratories. Data from the German Chest Pain Unit Registry. Int J Cardiol. 2017;231:31-5.

16. Brunetti ND, Amodio G, De Gennaro L, Dellegrottaglie G, Pellegrino PL, Di Biase M, et al. Telecardiology applied to a region-wide public emergency health-care service. J Thromb Thrombolysis. 2009;28:23-30. 
17. Amit G, Cafri C, Gilutz H, llia R, Zahger D. Benefit of the direct ambulance to coronary care unit admission of acute myocardial infarction patients undergoing primary percutaneous intervention. Int J Cardiol. 2007;119:355-8.

18. Brunetti ND, De Gennaro L, Correale M, Santoro F, Caldarola P, Gaglione A, et al. Pre-hospital electrocardiogram triage with telemedicine near halves time to treatment in STEMI: A meta-analysis and meta-regression analysis of non-randomized studies. Int J Cardiol. 2017;232:5-11

19. Han JN, Liu FQ. Ways for Win-Win Development of Large Public Hospitals and Primary Health Care Institutions Under Grading Diagnosis and Treatment. Modern Hospital. 2019;19:781-3.

20. Harhash AA, Huang JJ, Reddy S, Natarajan B, Balakrishnan M, Shetty R, et al. aVR ST Segment Elevation: Acute STEMI or Not? Incidence of an Acute Coronary Occlusion. Am J Med. 2019;132:62230.

21. Kopeć G, Waligóra M, Pacia M, Chmielak W, Stępień A, Janiec S, et al. Electrocardiogram reading: a randomized study comparing 2 e-learning methods for medical students. Pol Arch Intern Med. 2018;128:98-104

22. Patel K, E Tokhy O, Patel S, Maroof H. Improving electrocardiogram interpretation skills for medical students. Adv Med Educ Pract. 2017; 8:75-8.

23. Dumotier BM. A straightforward guide to the basic science behind arrhythmogenesis. 2014;100:190715.

24. Nattel S, Xiong F, Aguilar M. Demystifying rotors and their place in clinical translation of atrial fibrillation mechanisms. Nat Rev Cardiol. 2017;14:509-20.

25. Kodra A, Rambhatla T, Patel S, Coplan N. Assessing the competency of internal medicine residents in electrocardiogram interpretation. Int J Cardiol. 2016;214:288-90.

26. Cairns AW, Bond RR, Finlay DD, Breen C, Guldenring D, Gaffney R, et al. A computer-human interaction model to improve the diagnostic accuracy and clinical decision-making during 12-lead electrocardiogram interpretation. J Biomed Inform. 2016;64:93-107.

\section{Tables}

Table 1 Scoring criteria for 20 types of common ECGs 


\begin{tabular}{|c|c|c|c|}
\hline $\begin{array}{l}\text { Casing } \\
\text { hemodynamic } \\
\text { disorders and } \\
\text { life-threatening[3 } \\
\text { points } \square\end{array}$ & $\begin{array}{l}\text { Potentially causing } \\
\text { hemodynamic } \\
\text { disorders and life- } \\
\text { threatening } 2 \text { points } \square\end{array}$ & $\begin{array}{l}\text { Unconspicuous } \\
\text { causing hemodynamic } \\
\text { disorders and life- } \\
\text { threatening } 1 \text { points }[\end{array}$ & $\begin{array}{l}\text { Cannot interpret } \\
\text { any } \\
\text { electrocardiogram } \\
\text { व0 points }]\end{array}$ \\
\hline Myocardial infarction & Sinus tachycardia & Normal electrocardiogram & \\
\hline Ventricular flutter & Sinus cardiac arrest & Sinus bradycardia & \\
\hline Ventricular fibrillation & Left ventricular hypertrophy & Sinus block & \\
\hline Atrioventricular block & Right ventricular hypertrophy & Right bundle branch block & \\
\hline \multirow[t]{6}{*}{ Cardiac arrest } & Room sex premature beat & Left bundle branch block & \\
\hline & Ventricular premature beat & & \\
\hline & Atrial flutter & & \\
\hline & Atrial fibrillation & & \\
\hline & Preexcitation syndrome & & \\
\hline & Sick sinus syndrome & & \\
\hline
\end{tabular}

\section{Table 2 Scoring criteria for 10 types of critical ECGs}




\begin{tabular}{lll}
\hline $\begin{array}{l}\text { Casing hemodynamic } \\
\text { disorders and life- } \\
\text { threatening[2 points }[\end{array}$ & $\begin{array}{l}\text { Potentially causing } \\
\text { hemodynamic disorders and life- } \\
\text { threatening } 01 \text { points } \square\end{array}$ & $\begin{array}{l}\text { Cannot interpret any } \\
\text { points }[\end{array}$ \\
\hline Acute myocardial infarction & Hyperkalemia & \\
Acute pulmonary embolism & Acute pericarditis \\
Aortic dissection & Hypokalemia \\
Massive pericardial effusion & High calcium crisis \\
Cardiac arrest & \\
\hline
\end{tabular}

\section{Table 3 Scoring criteria for 10 types of ECGs}

\begin{tabular}{|c|c|c|c|}
\hline $\begin{array}{l}\text { Casing } \\
\text { hemodynamic } \\
\text { disorders and life- } \\
\text { threatening } \square 3 \\
\text { points } \square\end{array}$ & $\begin{array}{l}\text { Potentially causing } \\
\text { hemodynamic } \\
\text { disorders and life- } \\
\text { threatening[2 points }]\end{array}$ & $\begin{array}{l}\text { Unconspicuous causing } \\
\text { hemodynamic disorders } \\
\text { and life-threatening } 1 \\
\text { points } \square\end{array}$ & $\begin{array}{l}\text { False or } \\
\text { unclear } \\
\text { interpretation } \amalg 0 \\
\text { points } \square\end{array}$ \\
\hline $\begin{array}{l}\text { Question 1: Ventricular } \\
\text { fibrillation }\end{array}$ & $\begin{array}{l}\text { Question 3: Myocardial ischemia } \\
\text { Question 6: Brugada syndrome }\end{array}$ & Question 2: Normal electrocardiogram & \\
\hline $\begin{array}{l}\text { Question 4: No pulsating } \\
\text { electrical activity }\end{array}$ & Question 7: Atrial fibrillation & & \\
\hline $\begin{array}{l}\text { Question 5: Cardiac arrest } \\
\text { Question 8: Acute anterior } \\
\text { myocardial infarction }\end{array}$ & $\begin{array}{l}\text { Question 9: hyperkalemia } \\
\text { Question 10: Paroxysmal } \\
\text { supraventricular tachycardia }\end{array}$ & & \\
\hline
\end{tabular}




\begin{tabular}{|c|c|c|c|}
\hline \multicolumn{2}{|c|}{ Basic Information } & \multirow{2}{*}{$\frac{\text { Number of Cases (n) }}{553}$} & \multirow{2}{*}{$\frac{\text { Percentage (\%) }}{24.0}$} \\
\hline Region & Eastern China & & \\
\hline & South China & 166 & 7.1 \\
\hline & Central China & 197 & 8.6 \\
\hline & North China & 894 & 38.7 \\
\hline & Northwest China & 200 & 8.6 \\
\hline & Southwest China & 197 & 8.6 \\
\hline & Northeast China & 100 & 4.4 \\
\hline \multirow[t]{4}{*}{ Age (Y) } & $20-30$ & 281 & 12.2 \\
\hline & $30-40$ & 467 & 20.2 \\
\hline & $40-50$ & 1007 & 43.6 \\
\hline & $\geq 50$ & 552 & 23.9 \\
\hline \multirow[t]{4}{*}{ Education Background } & Junior College and Below & 759 & 32.9 \\
\hline & Bachelor Degree & 800 & 34.7 \\
\hline & Master Degree & 507 & 22.0 \\
\hline & Doctoral Degree & 241 & 104 \\
\hline \multirow[t]{2}{*}{ Occupational Identity } & Clinician & 1927 & 83.5 \\
\hline & Nurse & 380 & 16.5 \\
\hline \multirow[t]{5}{*}{ Professional Qualifications } & Physician Assistant & 993 & 43.0 \\
\hline & Primary Physician & 576 & 25.0 \\
\hline & Intermediate Physician & 423 & 18.3 \\
\hline & Associate Senior Physician & 170 & 7.4 \\
\hline & Senior Physician & 145 & 6.3 \\
\hline \multirow[t]{5}{*}{ Hospital Level } & Clinic & 65 & 2.8 \\
\hline & Class-I Hospital & 305 & 13.2 \\
\hline & Class- $\square$ Hospital & 1117 & 48.4 \\
\hline & Private Hospital & 215 & 9.3 \\
\hline & Class- $\square$ Hospital & 605 & 26.2 \\
\hline Total & & 2307 & 100.0 \\
\hline
\end{tabular}

Table 5 The distribution of electrocardiographic examination in all levels of hospitals in China 


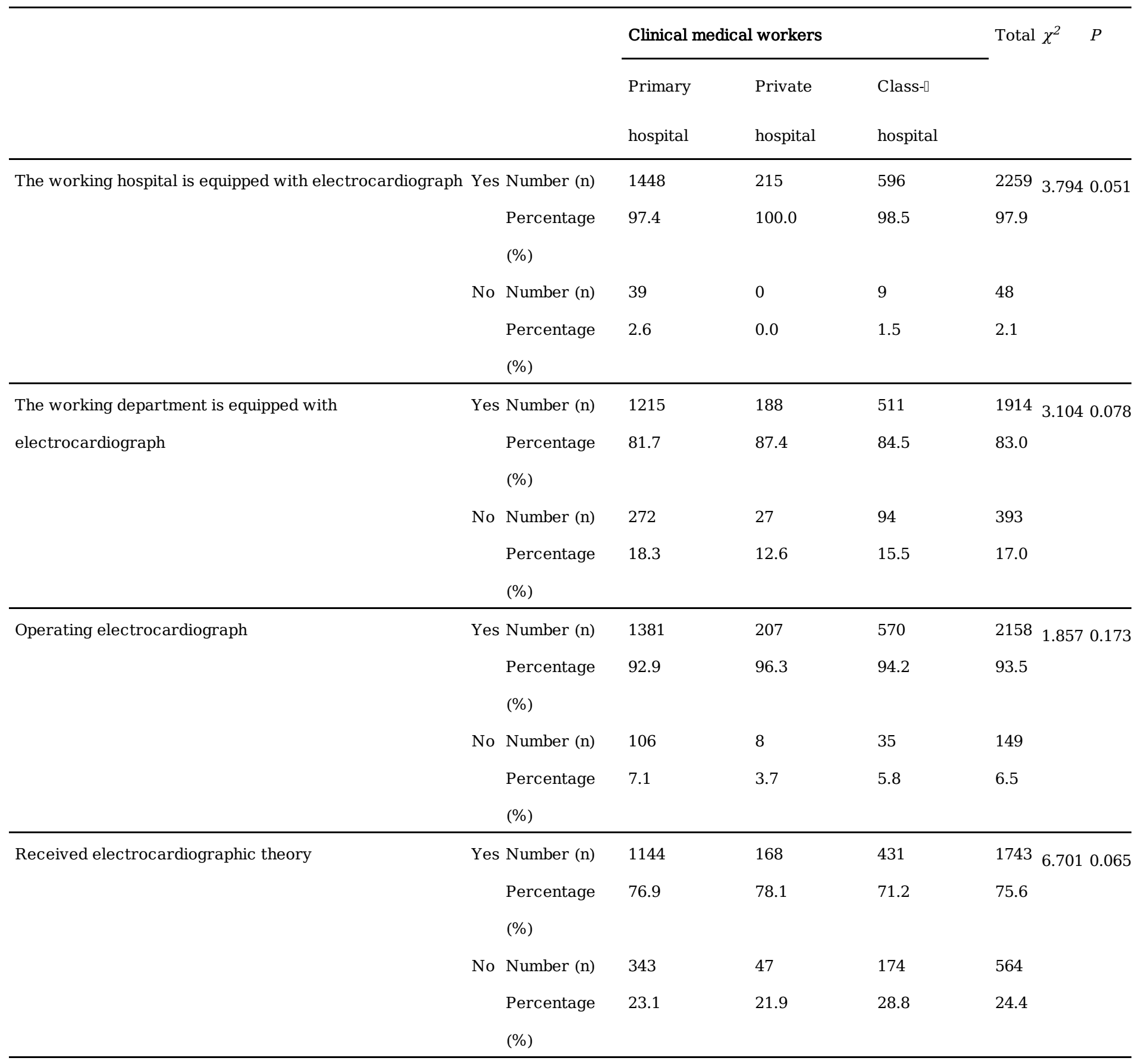

\section{Table 6 The characteristics of the age distribution of medical workers in hospitals of different rank}




\begin{tabular}{|c|c|c|c|c|c|c|c|c|}
\hline & & & \multicolumn{3}{|c|}{ Clinical medical workers } & \multirow[b]{2}{*}{ Total } & \multirow[b]{2}{*}{$x^{2}$} & \multirow[b]{2}{*}{$P$} \\
\hline & & & Primary hospital & Private hospital & Class- $-\square$ hospital & & & \\
\hline \multirow[t]{8}{*}{ Age (Y) } & $20-30$ & Number (n) & 109 & 39 & 133 & 281 & 50.93 & 0.000 \\
\hline & & Percentage (\%) & 7.3 & 18.1 & 22.0 & & & \\
\hline & $30-40$ & Number (n) & 203 & 33 & 231 & 467 & 147.51 & 0.000 \\
\hline & & Percentage (\%) & 13.7 & 15.3 & 38.2 & & & \\
\hline & $40-50$ & Number (n) & 715 & 91 & 201 & 1007 & 661.05 & 0.000 \\
\hline & & Percentage (\%) & 48.1 & 42.3 & 33.2 & & & \\
\hline & $\geq 50$ & Number (n) & 460 & 52 & 40 & 552 & 621.39 & 0.000 \\
\hline & & Percentage (\%) & 30.9 & 24.2 & 6.6 & & & \\
\hline
\end{tabular}

Table 7 The characteristics of education background distribution of medical workers in hospitals of different rank 


\begin{tabular}{|c|c|c|c|c|c|c|c|c|}
\hline & & & \multicolumn{3}{|c|}{$\begin{array}{c}\text { Clinical medical } \\
\text { workers }\end{array}$} & \multirow{3}{*}{ Total } & \multirow{3}{*}{$x^{2}$} & \multirow{3}{*}{$P$} \\
\hline & & & Primary & Private & Class- $\square$ & & & \\
\hline & & & hospital & hospital & hospital & & & \\
\hline Education & Junior College & Number (n) & 697 & 57 & 5 & 759 & 1175.91 & 0.000 \\
\hline \multirow[t]{11}{*}{ Background } & and Below & Percentage & 46.9 & 28.4 & 0.9 & & & \\
\hline & & $(\%)$ & & & & & & \\
\hline & Bachelor & Number (n) & 505 & 112 & 183 & 800 & 328.97 & 0.000 \\
\hline & Degree & Percentage & 34.0 & 52.1 & 30.2 & & & \\
\hline & & $(\%)$ & & & & & & \\
\hline & Master Degree & Number (n) & 254 & 25 & 228 & 507 & 186.05 & 0.000 \\
\hline & & Percentage & 17.1 & 11.6 & 37.7 & & & \\
\hline & & $(\%)$ & & & & & & \\
\hline & Doctoral & Number (n) & 31 & 17 & 193 & 241 & 238.24 & 0.000 \\
\hline & Degree & Percentage & 2.1 & 7.9 & 31.9 & & & \\
\hline & & (\%) & & & & & & \\
\hline
\end{tabular}

Table 8 The characteristics of professional qualifications distribution of medical workers in hospitals of different rank 


\begin{tabular}{|c|c|c|c|c|c|c|c|c|}
\hline & & & \multicolumn{3}{|c|}{$\begin{array}{c}\text { Clinical medical } \\
\text { workers }\end{array}$} & \multirow{3}{*}{ Total } & \multirow{3}{*}{$x^{2}$} & \multirow{3}{*}{$P$} \\
\hline & & & Primary & Private & Class- $\square$ & & & \\
\hline & & & hospital & hospital & hospital & & & \\
\hline Professional & Physician & Number (n) & 872 & 65 & 56 & 993 & 1326.41 & 0.000 \\
\hline \multirow[t]{14}{*}{ Qualification } & Assistant & Percentage & 58.6 & 30.2 & 9.3 & & & \\
\hline & & $(\%)$ & & & & & & \\
\hline & Primary & Number (n) & 467 & 47 & 62 & 576 & 591.41 & 0.000 \\
\hline & Physician & Percentage & 31.4 & 21.9 & 10.2 & & & \\
\hline & & $(\%)$ & & & & & & \\
\hline & Intermediate & Number (n) & 100 & 72 & 251 & 423 & 131.50 & 0.000 \\
\hline & Physician & Percentage & 6.7 & 33.5 & 41.5 & & & \\
\hline & & $(\%)$ & & & & & & \\
\hline & Associate Senior & Number (n) & 25 & 27 & 118 & 170 & 99.61 & 0.000 \\
\hline & Physician & Percentage & 1.7 & 12.6 & 19.5 & & & \\
\hline & & $(\%)$ & & & & & & \\
\hline & Senior Physician & Number (n) & 23 & 4 & 118 & 145 & 154.36 & 0.000 \\
\hline & & Percentage & 1.5 & 1.9 & 19.5 & & & \\
\hline & & (\%) & & & & & & \\
\hline
\end{tabular}

Table 9 The key aspects and useful methods to improve the electrocardiographic interpretation skills 
Number Percentage

(n)

(\%)

\begin{tabular}{|c|c|c|c|c|}
\hline $\begin{array}{l}\text { Whether the ECG interpretation skills are } \\
\text { helpful to clinical work } \square\end{array}$ & & $\begin{array}{l}\text { Yes } \\
\text { No }\end{array}$ & 2286 & $\begin{array}{l}99.1 \\
0.9\end{array}$ \\
\hline Which aspects are the key to improve ECG & A0The electrophysiological mechanism & Yes & 1605 & 69.6 \\
\hline interpretation skills $\square$ & that forms ECG & No & 702 & 30.4 \\
\hline & B: Characteristics of ECG in various & Yes & 2065 & 89.5 \\
\hline & diseases & No & 242 & 10.5 \\
\hline & C: Repeated clinical practice & Yes & 1913 & 82.9 \\
\hline & & No & 394 & 17.1 \\
\hline & D: To strengthen training & Yes & 1616 & 70.0 \\
\hline & & No & 691 & 30.0 \\
\hline & E: Combine practice with theory & Yes & 1921 & 83.3 \\
\hline & & No & 386 & 16.7 \\
\hline Which methods are helpful to improve & A: Learning through the Internet & Yes & 1649 & 71.5 \\
\hline ECG interpretation skills? & & No & 658 & 28.5 \\
\hline & B: Learning through ECG training course & Yes & 1466 & 63.5 \\
\hline & & No & 841 & 36.5 \\
\hline & C: Improve ECG teaching methods for & Yes & 1725 & 74.8 \\
\hline & medical students & No & 582 & 25.2 \\
\hline & D: Placing ECG readings in the medical & Yes & 1295 & 56.1 \\
\hline & area & No & 1012 & 43.9 \\
\hline & E: Improving the automatic analysis & Yes & 1605 & 69.6 \\
\hline & ability of electrocardiograph & No & 702 & 30.4 \\
\hline Total & & & 2307 & 100.0 \\
\hline
\end{tabular}

\section{Figures}




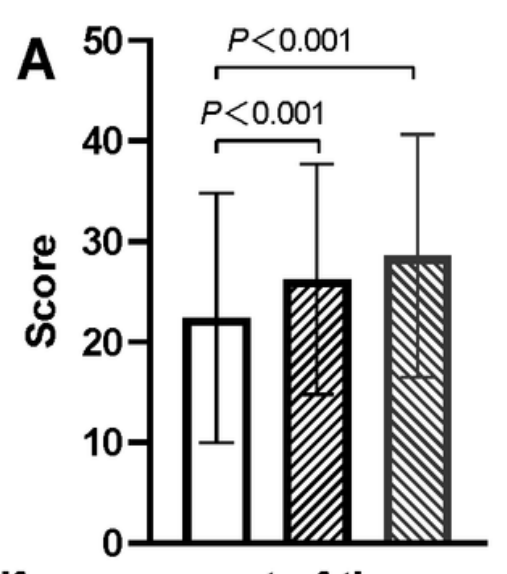

Self-assessment of the common ECG

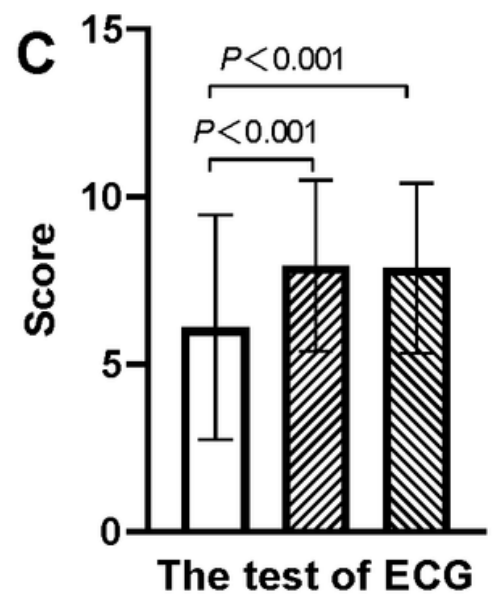

口 Primary hospital

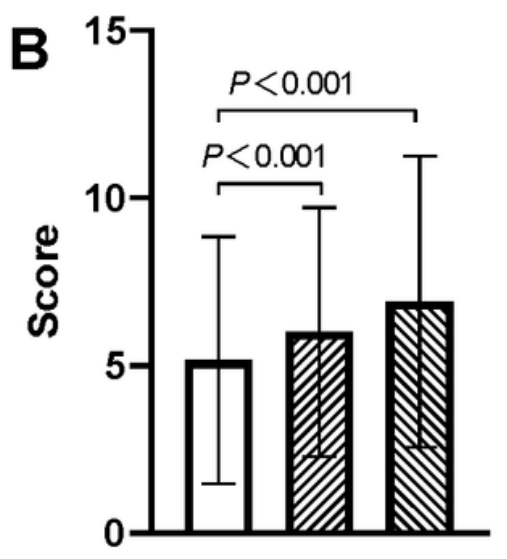

Self-assessment of the life-threatening ECG

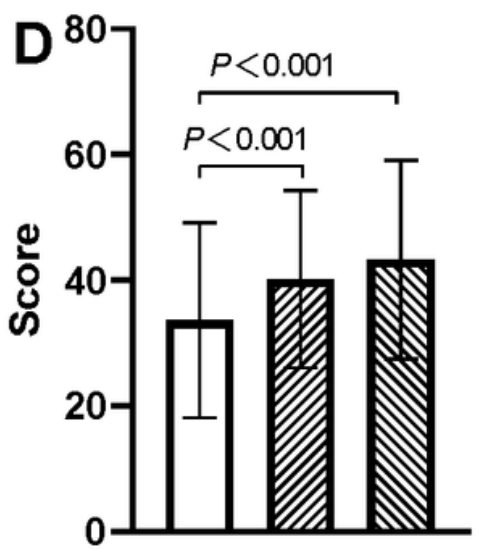

The competency of ECG interpretation skills

m Private hospital

Class- II hospital

Figure 1

The interpretation competency of ECG of medical workers in different levels of hospitals. The respondents were asked to self-assessed 20 types of commonly ECGs (A). The respondents were asked to self-assessed 10 types of life-threatening ECGs (B). The respondents were asked to choose the correct interpretation of the 10 types of electrocardiographic images that we provided (C). The total score of electrocardiographic self-assessment and test, which represented the interpretation competency of ECG of medical workers (D). Data were represented as mean \pm standard deviation (SD) and analyzed by the software of IBM SPSS Statistics 24 with a one-way ANOVA, A P-value of 0.05 or 0.01 was considered statistically significant. 

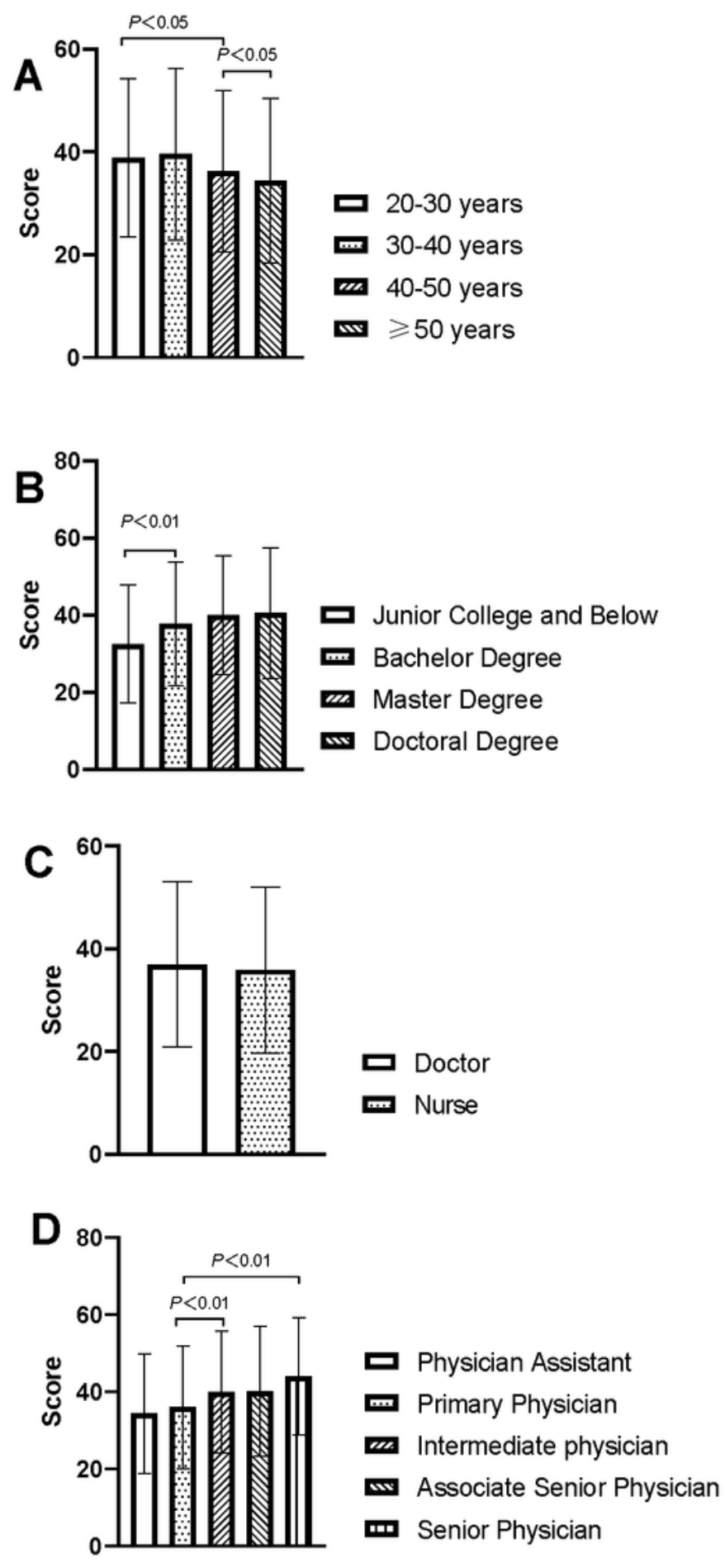

\section{Figure 4}

The effect of basic information on the interpretation competency of ECG. The effect of age on ECG interpretation skills (A). The effect of education background on ECG interpretation skills (B). The effect of occupational identity on ECG interpretation skills (C). The effect of professional qualifications on ECG interpretation skills (D). Data were represented as mean \pm standard deviation (SD) and analyzed by the 
software of IBM SPSS Statistics 24 with a one-way ANOVA, A P-value of 0.05 or 0.01 was considered statistically significant.
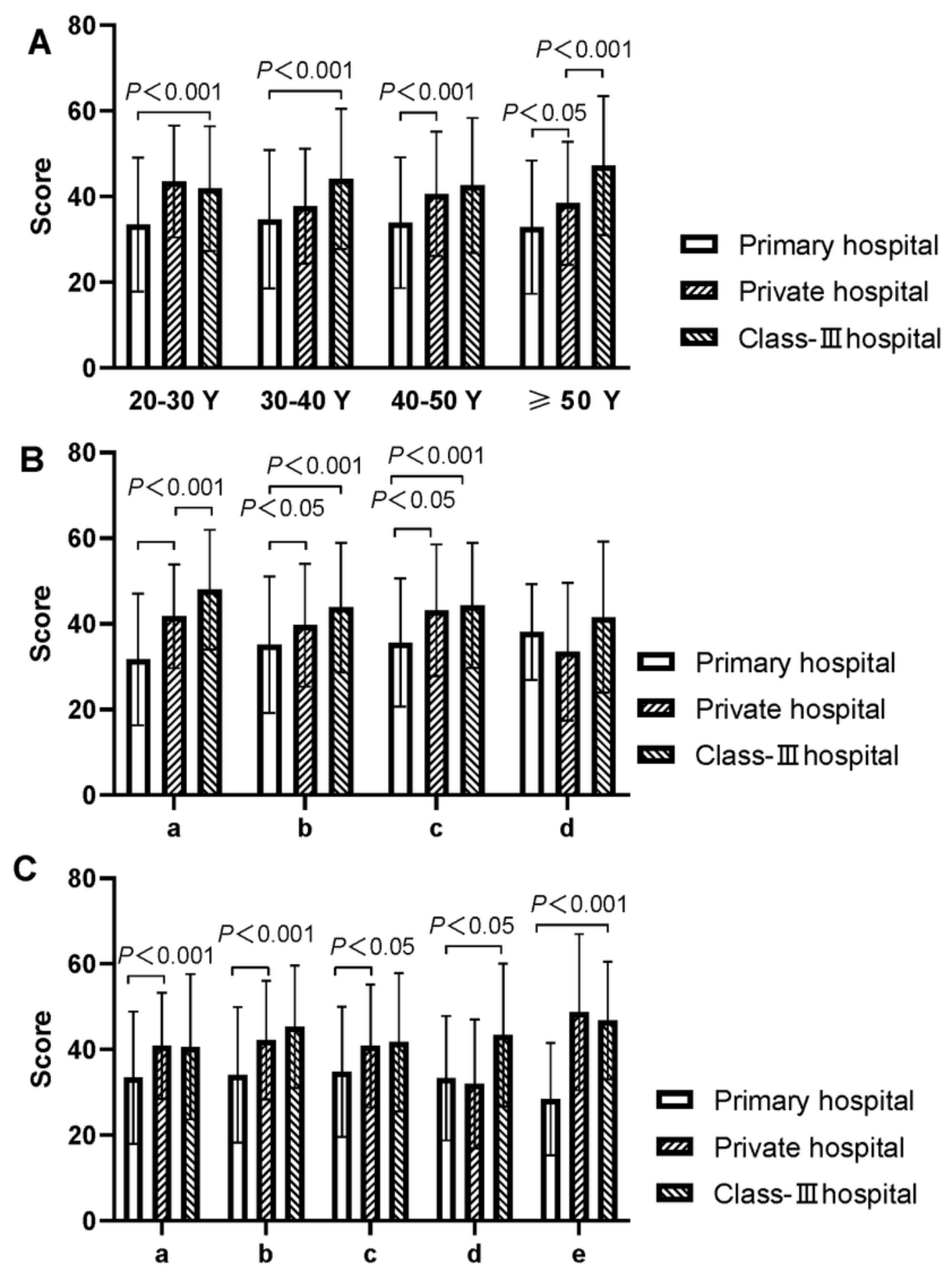

Figure 6

The effect of talent development on the interpretation competency of ECG. The effect of different age on ECG interpretation skills of primary clinical medical workers (A). The effect of different education background on ECG interpretation skills of primary clinical medical workers (B). a: Junior College and 
Below, b: Bachelor Degree, c: Master Degree, d: Doctoral Degree. The effect of different professional qualifications on ECG interpretation skills of primary clinical medical workers (C). a: Physician Assistant, b: Primary Physician, c: Intermediate Physician, d: Associate Senior Physician, e: Senior Physician. Data were represented as mean \pm standard deviation (SD) and analyzed by the software of IBM SPSS Statistics 24 with a one-way ANOVA, A P-value of 0.05 or 0.01 was considered statistically significant. 